\title{
PULMONARY ADENOCARCINOMA WITH OSSEOUS METASTASIS AND SECONDARY PARESIS IN A BLUE AND GOLD MACAW (ARA ARARAUNA)
}

\author{
Author(s): Daniel V. Fredholm, M.S., D.V.M., James W. Carpenter , M.S., \\ D.V.M., Dipl. A.C.Z.M., Loni L. Shumacher, D.V.M., and Rachel S. Moon , \\ D.V.M.
}

Source: Journal of Zoo and Wildlife Medicine, 43(4):909-913. 2012.

Published By: American Association of Zoo Veterinarians

DOI: http://dx.doi.org/10.1638/2012-0108R.1

URL: http://www.bioone.org/doi/full/10.1638/2012-0108R.1

BioOne (www.bioone.org) is a nonprofit, online aggregation of core research in the biological, ecological, and environmental sciences. BioOne provides a sustainable online platform for over 170 journals and books published by nonprofit societies, associations, museums, institutions, and presses.

Your use of this PDF, the BioOne Web site, and all posted and associated content indicates your acceptance of BioOne's Terms of Use, available at www.bioone.org/page/ terms of use.

Usage of BioOne content is strictly limited to personal, educational, and non-commercial use. Commercial inquiries or rights and permissions requests should be directed to the individual publisher as copyright holder. 


\title{
PULMONARY ADENOCARCINOMA WITH OSSEOUS METASTASIS AND SECONDARY PARESIS IN A BLUE AND GOLD MACAW $(A R A$ ARARAUNA)
}

\author{
Daniel V. Fredholm, M.S., D.V.M., James W. Carpenter, M.S., D.V.M., Dipl. A.C.Z.M., Loni L. \\ Shumacher, D.V.M., and Rachel S. Moon, D.V.M.
}

\begin{abstract}
A 16-yr-old female blue and gold macaw (Ara ararauna) was presented with an acute history of lethargy, inappetance, ataxia, and paralysis. The bird had rapidly progressed from a normal state to complete inability to perch or ambulate within a 48-hr period. Neurologic examination revealed bilateral hind limb paresis with upper motor neuron signs present in both legs and the vent. Radiographs identified multiple nodular softtissue opacities within the cranial coelomic cavity and a single nodule superimposed with the thoracic spine. The bird was euthanized and submitted for necropsy, which revealed a primary pulmonary adenocarcinoma with multiple sites of osseous metastasis, including the vertebrae, and subsequent spinal cord compression. This is the first report of pulmonary adenocarcinoma in this species, although reports of similar tumors in other psittacines have been published. This report, along with others previously published, suggests that vertebral metastasis of primary pulmonary tumors may be more common in psittacine species than previously recognized and, as such, should be considered as a differential diagnosis in psittacine birds exhibiting signs of neurologic dysfunction attributed to a spinal cord lesion.
\end{abstract}

Key words: $\quad$ adenocarcinoma, Ara ararauna, macaw, metastasis, paresis.

\section{CASE REPORT}

A 16-yr-old female blue and gold macaw (Ara ararauna) was presented with an acute history of lethargy, inappetance, ataxia, and paralysis. The bird had reportedly been acting normal $48 \mathrm{hr}$ prior to presentation but began to show signs of stumbling and incoordination, which progressed to an inability to perch or ambulate. There was no known previous history of illness, although the bird had had three previous owners and been in the care of its current owner for less than $1 \mathrm{yr}$. This bird was housed in an approximately $4 \mathrm{ft} \times 5$ $\mathrm{ft} \times 5 \mathrm{ft}$ metal cage that had numerous areas of rust on it. The diet provided to this bird was poor, consisting of seeds, nuts, frozen fruit, and table scraps.

On physical examination, the macaw was lethargic but responsive and remained in sternal recumbency even when stimulated to move. The bird weighed $0.8 \mathrm{~kg}$ and was considered to be in extremely poor body condition (keel score $1 / 5$ ). Overall, this patient was mildly dehydrated and had dull and disheveled feather condition with areas of feather loss over the keel and pectoral

From the Departments of Clinical Sciences (Fredholm, Carpenter, Moon) and Diagnostic Medicine/ Pathobiology (Shumacher), College of Veterinary Medicine, Kansas State University, Manhattan, Kansas 66506, USA. Correspondence should be directed to Dr. Fredholm(dfredholm@ufl.edu). region. The skin overlying the keel was erythematous with some mild abrasions, and there were similar lesions bilaterally on the carpi. Assessment of the vertebral column during palpation revealed good stability but a mild to moderate pain response over the midthoracic region.

Neurologic examination revealed normal cranial nerve function and normal function of both wings. Bilateral paresis of the hind limbs was noted, with minimal extensor postural thrust reaction and decreased proprioception bilaterally, with the right leg showing no proprioceptive response at all. Withdrawal response was found to be within normal limits to mildly hyperreflexive bilaterally, although a positive crossedextensor reaction was noted, and hyperreflexia was seen in the vent and both patellar tendons. Because birds lack cutaneous trunci muscles, testing for panniculus response to localize spinal lesions is not possible. ${ }^{6}$ Instead, subjective monitoring for pain response while twisting at the base of individual feathers can indicate cutaneous sensation. In this case, there appeared to be minimal pain response to feathers that were twisted in the caudal half of the body, although the responses were variable and difficult to interpret. There was no response to superficial noxious stimuli in either leg, although deep pain was present bilaterally.

Results of hematologic analysis were unremarkable. The only biochemical abnormality was an increase in creatine kinase $(1,511 \mathrm{U} / \mathrm{L}$; reference 
range, $180-500 \mathrm{U} / \mathrm{L}) .{ }^{10}$ Serum levels of zinc, lead, and copper were all evaluated and found to be within normal limits.

Whole body lateral and ventrodorsal view radiographs revealed multiple soft-tissue nodular opacities, ranging in size from 1 to $1.4 \mathrm{~cm}$, in the cranial half of the coelomic cavity. On the lateral view, one of these nodules was superimposed over the thoracic vertebra and another was visible caudal to the coracoid. There was also border effacement of the cardiac silhouette due to diffuse soft-tissue opacity in the cranioventral coelom and some mild periosteal reactive change in this area of the sternum (Fig. 1). On the ventrodorsal view, a nodule was superimposed over the caudolateral right lung field. There was also increased opacity in the area of the cardiohepatic silhouette.

Initial treatment included intravenous fluid therapy with lactated Ringer's solution at a rate of $75 \mathrm{~mL} / \mathrm{kg} / \mathrm{d}$, meloxicam (Metacam $1.5 \mathrm{mg} / \mathrm{mL}$ oral suspension, Boehringer Ingelheim Vetmedica, St. Joseph, Missouri 64506, USA) $0.2 \mathrm{mg} / \mathrm{kg}$ p.o. q 24 hr, butorphanol (Torbugesic, Fort Dodge Animal Health, Fort Dodge, Iowa 50501, USA) 4 $\mathrm{mg} / \mathrm{kg}$ i.m. q 4-6 hr, silver sulfadiazine (1\% cream, PAR Pharmaceutical Companies, Inc., Spring Valley, New York 10977, USA) topically q $12 \mathrm{hr}$ to the keel and carpal sores), and nutritional support via gavage feeding. Despite supportive care, the macaw's depression and weight loss persisted, and there was progressive loss of neurologic function in the hind limbs. Additional diagnostic imaging, including computed tomography and magnetic resonance imaging, were offered but declined due to financial constraints. Three days after presentation, there was total loss of function and deep pain sensation in the right leg, along with near-total loss of sensation in the left leg. In addition, the bird began to develop decubital ulceration of the skin overlying the keel. Considering the poor prognosis and financial challenges, the macaw was euthanized and submitted for necropsy.

On gross necropsy examination, the peritoneal surface of the sternum contained a $1.5 \mathrm{~cm} \times 3 \mathrm{~cm}$, white to tan, irregular, spiculated, poorly demarcated mass that effaced and replaced the proximal one third of the bone. The tissue was intimately attached to the periosteum of the sternum and felt gritty on cut section. The right edge of the sternum had three approximately $4 \mathrm{~mm}$ diameter white, firm, nodular masses. Similar nodular masses, ranging in size from 0.5 to $1 \mathrm{~cm}$ in diameter, were present on the costochondral junctions, rib bodies, rib tubercles, and costover- tebral joints of left ribs 7 and 8 (Fig. 2). In addition, a semifirm, tan, nodular mass was present on the right side of the vertebral column, adhered to and seemingly involving the pulmonary parenchyma. On cross-section, the masses associated with the vertebral column appeared to extend through the thoracic vertebral bodies of 7 and 8 and into the vertebral canal. The infiltrative tissue compressed and distorted the spinal cord while obliterating most of vertebral bodies 7 and 8 (Fig. 3). Sections of formalin fixed tissues were submitted for histopathologic evaluation.

Microscopically, sections of pulmonary tissue contain an expansile, unencapsulated mass directly attached to and infiltrating into lung parenchyma. The mass was regionally extensive, and it expanded and obliterated surrounding parenchyma. The mass consisted of immature, well-vascularized, and disorganized granulation tissue with plump cuboidal to polygonal epithelial cells arranged in nests of tubuloacinar structures, which were separated by thick bands of desmoplastic stroma. Acinar structures were lined by columnar to cuboidal epithelium that had eosinophilic vacuolated cytoplasm or cytoplasm filled with mucus characteristic of goblet cells. Many centers of acinar structures were filled with mucus or formed multiple coalescing lakes of mucus (Fig. 4).

Sections of tissue from the peritoneal surface of the sternum, left ribs 7 and 8 , and thoracic vertebrae 7 and 8 had similar neoplastic tissue that effaced and replaced bone trabeculae and adjacent vertebral air spaces and filled spaces between trabeculae. In these sections, mature remnants of bone were admixed with tubuloacinar structures lined by mucus-filled globet cells and vacuolated epithelial cells. Within thoracic vertebrae 7 and 8, neoplastic tissue focally infiltrated through vertebral bodies, invaded into the vertebral canal, and compressed and distorted the spinal cord (Fig. 5). There was less mucus and granulation tissue in sections of the sternum, ribs, and vertebrae than in the lung.

A diagnosis of bronchial gland carcinoma was made on the basis of goblet cell-lined epithelium, predominance in lung tissue, and the desmoplastic or scirrhous response typical of carcinomas. Histopathology confirmed metastases to the sternum, ribs, and vertebral bodies, with invasion into the spinal canal and subsequent compression of the spinal cord, leading to the clinical signs of neurologic dysfunction. There were no gross or microscopic lesions in the kidney, adrenal gland, thyroid gland, heart, liver, spleen, peripheral 


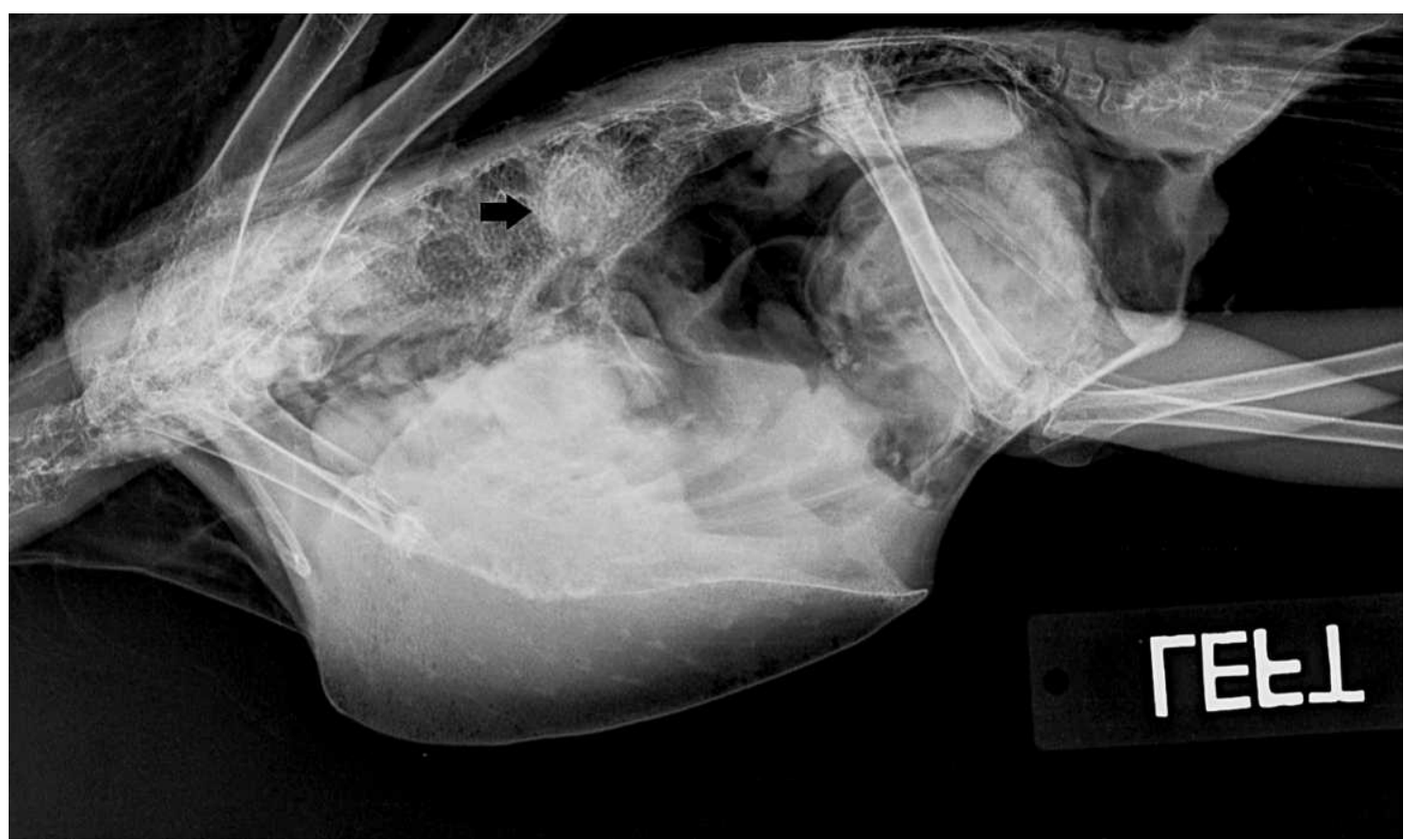

Figure 1. Left lateral radiograph of a blue and gold macaw with an acute history of bilateral hindlimb paresis. There are multiple soft-tissue nodular opacities in the cranial half of the coelomic cavity. Note the soft-tissue opacity superimposed over the thoracic vertebrae (arrow).

nerve, skeletal muscle, ingluvies, proventriculus, ventriculus, small intestine, ceca, colon, cloaca, and brain.

\section{DISCUSSION}

Primary pulmonary neoplasms are infrequent occurrences in dogs and cats, with estimates of incidence being $1 \%$ or less. ${ }^{19}$ In birds, primary

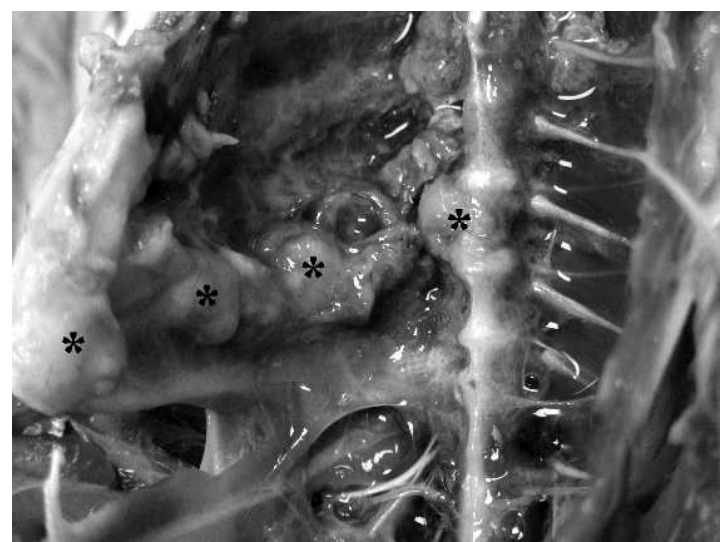

Figure 2. Gross image of left ribs 7 and 8 in the bird in Figure 1. White to tan nodules are present along the costochondral junctions, rib bodies, rib tubercles, and costovertebral joints (asterisks). lower respiratory tract neoplasia is similarly rare, accounting for approximately $0.1-0.3 \%$ of all avian neoplasms. ${ }^{7,13,18}$ To the authors' knowledge, this is the first reported case of a primary pulmonary adenocarcinoma in a blue and gold macaw.

Primary pulmonary carcinomas have been reported in other pstittacine species, including an

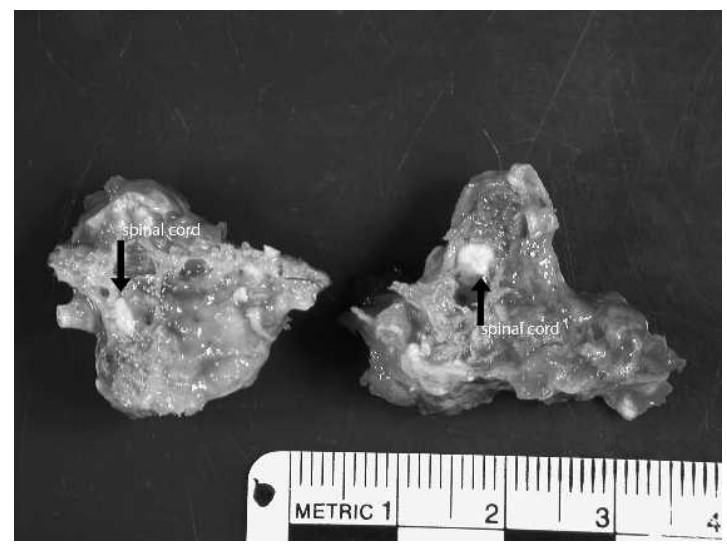

Figure 3. Gross transverse sections of thoracic vertebral bodies 7 and 8 of the bird in Figure 1. The mucinous neoplastic tissue has obliterated bone and severely compressed and distorted the spinal canal (black arrows). 


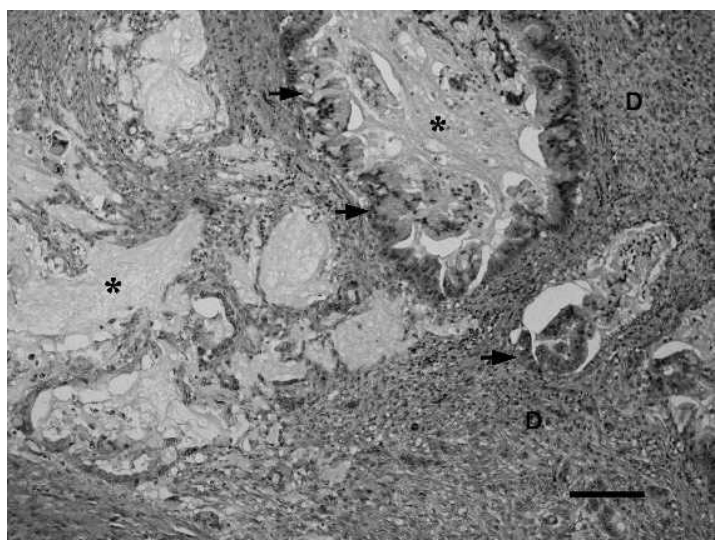

Figure 4. Photomicrograph of a pulmonary adenocarcinoma from the bird in Figure 1. The tumor is composed of nests of tubuloacinar structures, which are lined by columnar to cuboidal epithelium and have eosinophilic vacuolated cytoplasm or goblet cell-like cytoplasm (arrows). Many structures have centers of mucus or form coalescing lakes of mucus (asterisks) and are separated by abundant desmoplastic stroma (D). (H\&E stain, bar $=100 \mu \mathrm{m})$.

African grey parrot (Psittacus erithacus) $)^{1}$, a moluccan cockatoo (Cacatua moluccensis) ${ }^{11}$, and a hyacinth macaw (Anodorynchus hyacinthinus) ${ }^{2}$. Other primary lower respiratory neoplasms that have been reported in psittacines include a pulmonary fibrosarcoma in a cockatiel (Nymphicus hollandicus) ${ }^{13}$ and an air sac fibrosarcoma in a yellowheaded Amazon parrot (Amazona ochrocephala oratrix). ${ }^{5}$

Generally, metastatic disease in avian neoplasia is an uncommon occurrence, with one survey estimating a rate of $4.5 \% .{ }^{13}$ However, in the three previous reports of primary pulmonary carcinomas of psittacines, all reported osseous metastasis to the right humerus, ${ }^{1}$ the vertebral column, ${ }^{2}$ or both. ${ }^{11}$ In both the case of the hyacinth macaw and of the moluccan cockatoo, metastasis to the vertebral column and subsequent invasion of the spinal canal led to posterior paresis with striking similarities to this report. Although sample size is clearly limited, it is interesting that there is a relatively increased incidence of metastasis (specifically to bone) in these cases when compared with all avian neoplasia. One possible explanation for this tendency is the connection that exists between the avian skeletal and respiratory systems. The physiologic adaptation of pneumatic bone, which allows for easier flight, involves a direct communication between avian lungs, air sacs, and bones lined with respiratory epithelium. Osseous metastasis of primary pulmonary tumors

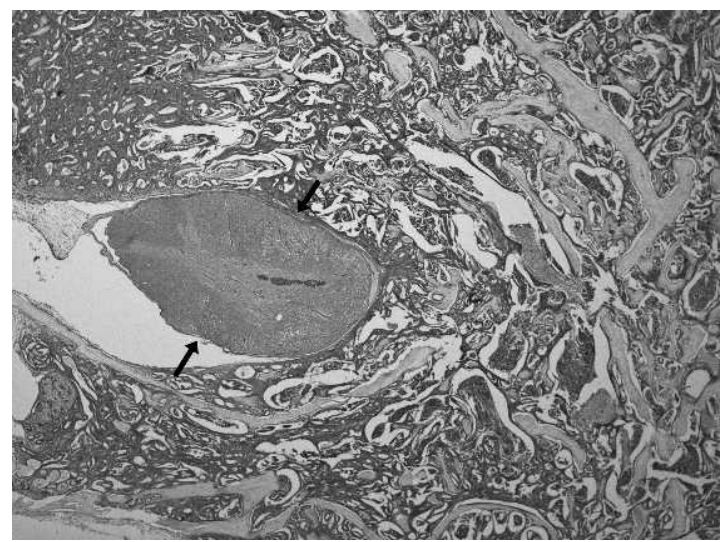

Figure 5. Photomicrograph of the spinal cord of the bird from Figure 1. Note that the tumor has obliterated vertebral bone, invaded the vertebral canal, and compressed the spinal cord (black arrows). (H\&E stain, $\times 10)$.

is reported in other species as well, with digital lytic lesions in cats being a commonly recognized, albeit poorly understood, syndrome. ${ }^{19}$

Differential diagnoses for acute paraparesis in birds include toxicoses (e.g., heavy metals, carbamates, organophosphates, organochlorides), infectious agents (e.g., bornaviruses, herpesviruses, retroviruses, paramyxoviruses, Chlamydophila psittaci, Mycobacterium avium, Aspergillus, Candida, Toxoplasma), neoplasia, vascular abnormality, inflammatory disease, trauma, nutritional deficiencies, and metabolic disease. ${ }^{3,4,8,9,12,14-17}$ In this case, lack of abnormalities on blood work, combined with neurologic examination findings and radiographic evidence, all supported a severe spinal cord lesion, likely neoplastic in origin. Considering the complete lack of any respiratory abnormalities, a primary respiratory disease was not considered likely but was subsequently diagnosed on necropsy and histopathology. Similarly, none of the previously mentioned reports of primary pulmonary adenocarcinoma have noted any signs of respiratory compromise. The only mention of noticeable respiratory distress in these reports was in the hyacinth macaw, and this occurred only after anesthesia for diagnostic imaging.

Although cases of avian primary pulmonary adenocarcinoma remain rare, the very few reports that exist seem to suggest that the presenting clinical picture does not commonly include respiratory signs but, instead, focuses on signs related to osseous metastasis. These few cases also preliminarily seem to indicate that metastasis to bone may be a common finding. That being said, 
further research into the actual incidence of this disease and any sequelae would be required to confirm or refute a true correlation between primary pulmonary adenocarcinoma and vertebral metastasis. Despite this, primary pulmonary tumors should at least be considered as a differential diagnosis in psittacines exhibiting signs of osseous neoplasia and in birds presenting with neurologic dysfunction attributed to a spinal cord lesion.

\section{LITERATURE CITED}

1. Andre, J. P., and M. Delverdier. 1999. Primary bronchial carcinoma with osseous metastasis in an African grey parrot (Psittacus erithacus). J. Avian Med. Surg. 13: 180-186.

2. Baumgartner, W. A., D. S. Guzman, S. Hollibush, L. Gaschen, E. C. Hodgin, and M. A. Mitchell. 2008. Bronchogenic adenocarcinoma in a hyacinth macaw (Anodorhynchus hyacinthinus). J. Avian Med. Surg. 22: 218-225.

3. Bennett, R. A. 1994. Neurology. In: Ritchie, B. W., G. J. Harrison, and L. R. Harrison (eds.). Avian Medicine: Principles and Applications. Wingers Publishing, Lake Worth, Florida. Pp. 723-747.

4. Billington, S. 2005. Clinical and zoonotic aspects of psittacosis. In. Pract. 27: 256-263.

5. Burgmann, P. M. 1994. Pulmonary fibrosarcoma with hepatic metastasis in a cockatiel (Nymphicus hollandicus). J. Assoc. Avian Vet. 8: 81-84.

6. Clippinger, T. L., R. A. Bennett, and S. R. Platt. 1996. The avian neurologic examination and ancillary neurodiagnostic techniques. J. Avian Med. Surg. 10: 221-247.

7. Garner, M. M. 2006. Overview of tumors: section II. In: Harrison, G. J., and T. L. Lightfoot (eds.). Clinical Avian Medicine. Vol. II. Spix Publishing, Palm Beach, Florida. Pp. 566-571.

8. Goodwin, M. A., J. P. Dubey, and J. Hatkin. 1994. Toxoplasma gondii peripheral neuritis in chickens. J. Vet. Diagn. Invest. 6: 382-385.
9. Greenacre, C. B., K. S. Latimer, and B. W. Ritchie. 1992. Leg paresis in a black palm cockatoo (Probosciger aterrimus) caused by aspergillosis. J. Zoo Wildl. Med. 23:122-126.

10. Hawkins, M. G., H. W. Barron, B. L. Speer, C. Pollock, and J. W. Carpenter. 2013. Birds. In: Carpenter, J. W. (ed.). Exotic animal formulary, 4th ed. Elsevier, St. Louis, Missouri. Pp. 183-437.

11. Jones, M. P., S. E. Orosz, L. K. Richman, G. B. Daniel, and P. N. Bochsler. 2001. Pulmonary carcinoma with metastases in a Moluccan cockatoo (Cacatua moluccensis). J. Avian Med. Surg. 15: 107-113.

12. Keller, D. L., K. S. Honkavuori, T. Briese, W. I. Lipkin, A. Muthuswamy, H. Steinberg, and K. K. Sladky. 2010. Proventricular dilatation disease associated with avian bornavirus in a scarlet macaw (Ara macao). J. Vet. Diagn. Invest. 22: 961-965.

13. Leach, M. W. 1992. A survey of neoplasia in pet birds. Semin. Avian Exotic Pet Med. 1: 52-64.

14. Leach, M. W., R. J. Higgins, L. J. Lowenstine, and B. Shor. 1988. Paramyxovirus infection in a Moluccan cockatoo (Cacatua moluccensis) with neurological signs. Assoc. Avian Vet. Today 2: 87-90.

15. Paul-Murphy, J., L. Lowenstine, J. M. Turrel, C. J. Murphy, and M. E. Fowler. 1985. Malignant lymphoreticular neoplasm in an African gray parrot. J. Am. Vet. Med. Assoc. 187: 1216-1217.

16. Rae, M. 1995. Endocrine disease in pet birds. Semin. Avian Exotic Pet. Med. 4: 32-38.

17. Stauber, E., M. Papageorges, R. Sande, and L. Ward. 1990. Polyostotic hyperostosis associated with oviductal tumor in a cockatiel. J. Am. Vet. Med. Assoc. 196: 939-940.

18. Stewart, H. L. 1966. Pulmonary cancer and adenomatosis in captive wild mammals and birds from the Philadelphia zoo. J. Natl. Cancer Inst. 36: 117-138.

19. Withrow, S. J. 2007. Tumors of the respiratory system. In: Withrow, S. J., and D. M. Vail (eds.). Small Animal Clinical Oncology, 4th ed. Elsevier, St. Louis, Missouri. Pp. 517-523.

Received for publication 26 April 2012 